\title{
Horizontal Bone Augmentation with the Cortical Lamina Technique: A Case Report
}

\author{
Edoardo Foce and Roberto Rossi* \\ Torre San Vincenzo 2, 16121 Genova, Italy
}

*Corresponding author: Roberto Rossi, Torre San Vincenzo, Genova, Italy

\begin{tabular}{|c|c|}
\hline ARTICLE INFO & ABSTRACT \\
\hline Received: 輩 April 19, 2021 & $\begin{array}{l}\text { Citation: Edoardo Foce, Roberto Rossi. Horizontal Bone Augmentation with the } \\
\text { Cortical Lamina Technique: A Case Report. Biomed J Sci \& Tech Res 35(3)-2021. BJSTR. }\end{array}$ \\
\hline Published: 幽 April 27, 2021 & MS.ID.005693. \\
\hline
\end{tabular}

\section{Introduction}

A female patient 28 years old was referred by the orthodontist to complete her dental treatment. Patient presented with several missing teeth due to agenesis, she had only two upper permanent molars and a deciduous one in the lower right side. The request of the patient was to replace two lower molars and one in the upper right side in order to restore proper occlusion (Figures 1-3). As part of the study case the patient was sent for a CBCT in order to evaluate the condition of the edentulous areas (Figure 4) [1].

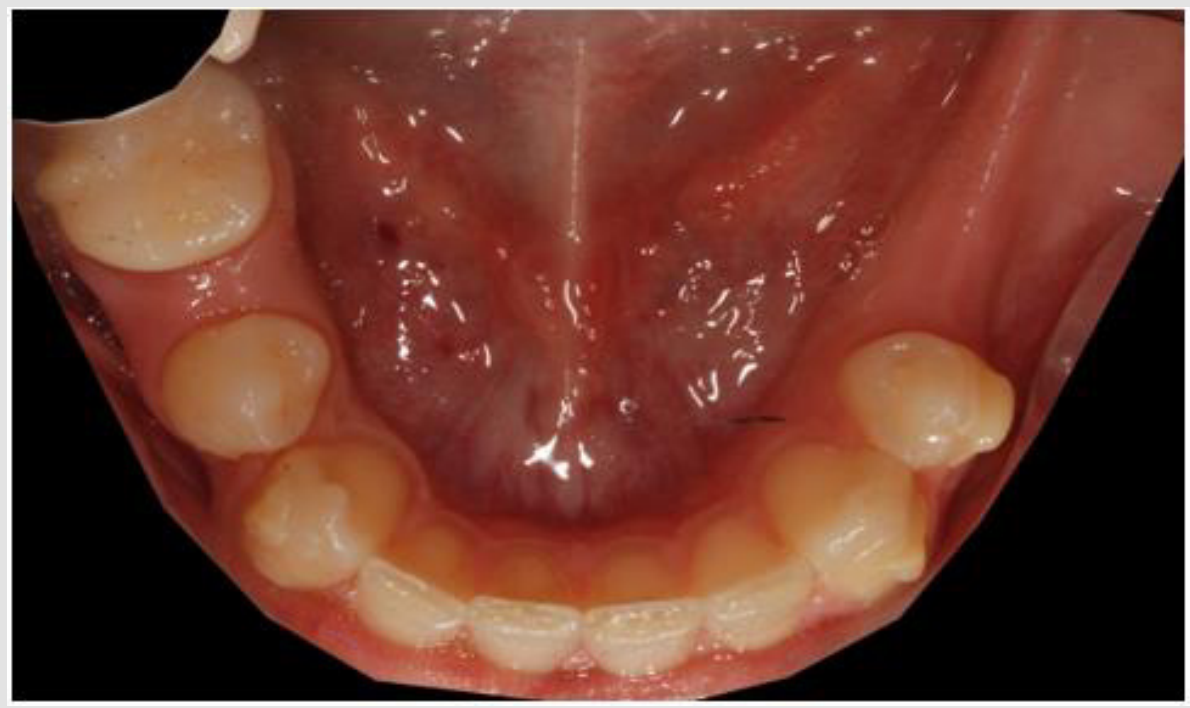

Figure 1: initial situation. 


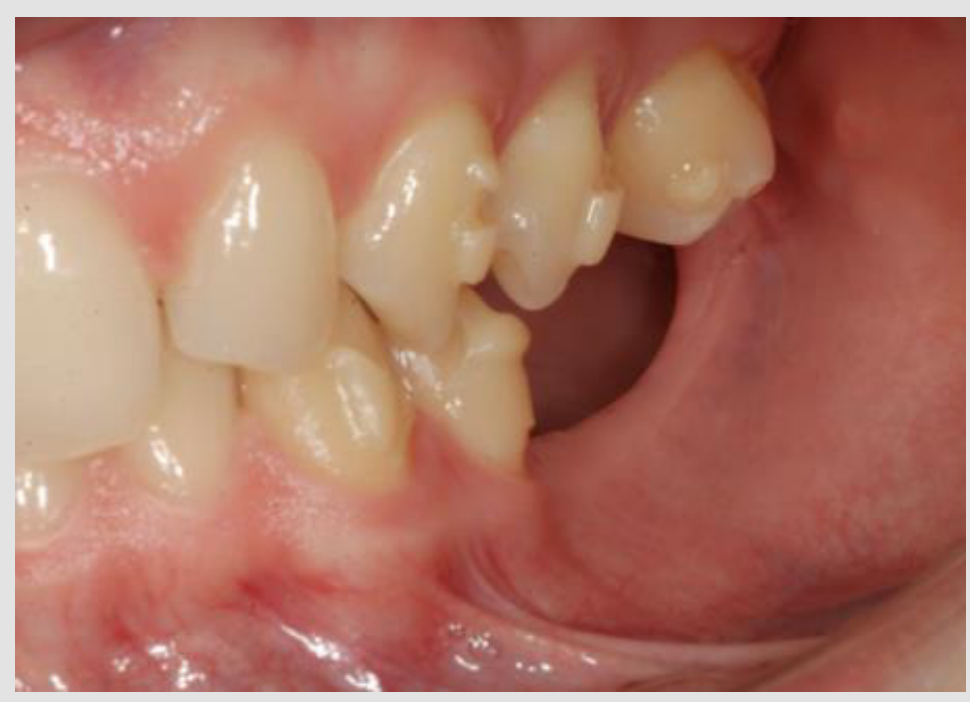

Figure 2: Lower left quadrant.

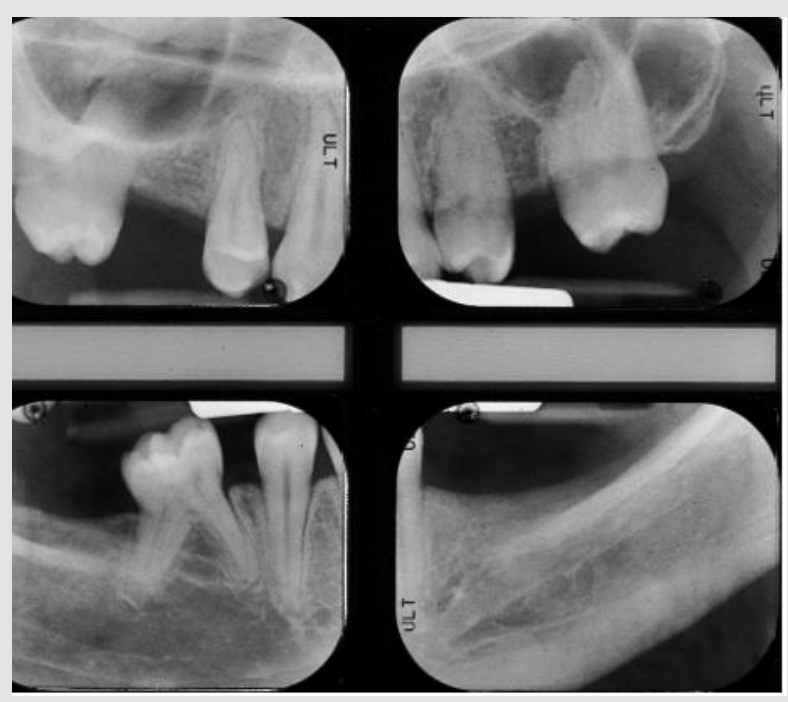

Figure 3: Peri-apical rx.

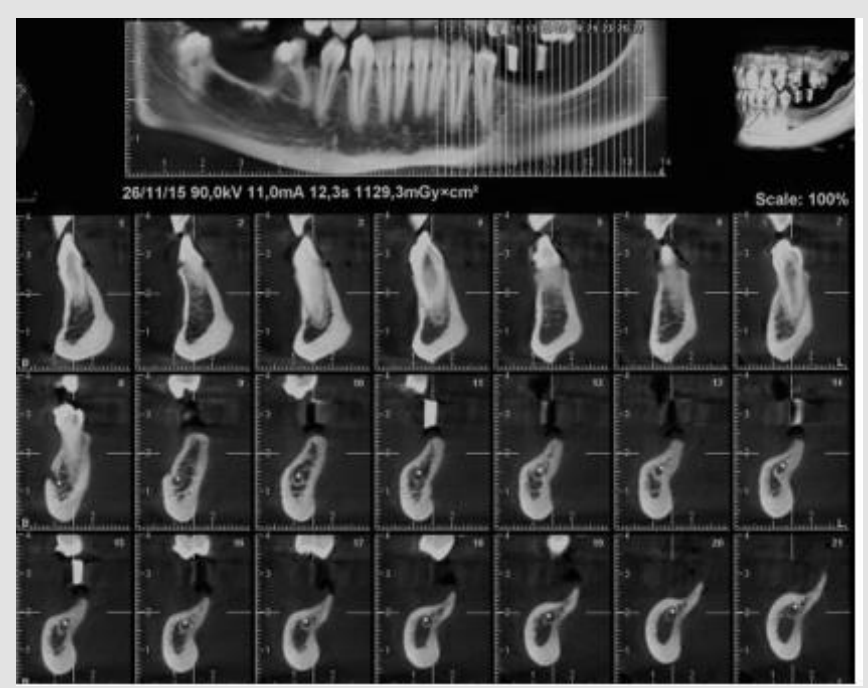

Figure 4: CBCT of the lower arch. The mandibular nerve runs very superficial. 
Unfortunately, the 3D evaluation showed a severe type of horizontal bone resorption in both molar areas, right and left. Priority was given to the lower left side where one bicuspid and all three molars were missing. Nevertheless, the anatomy of the area showed how the combination of horizontal bone loss plus very superficial mandibular canal would allow the placement of one only implant. As part of the planning, stone casts were taken and with the aid of periodontal probes was evaluated the kind of augmentation needed (Figure 5). In order to accommodate a standard diameter implant was requested an augmentation of at least 5-6 mm. It was decided to address this area with the aid of a bone lamina (Cortical Lamina, OsteoBiol by Tecnoss, Coazze, Italy) technique associated with a mix of autogenous bone mixed with collagenated porcine bone graft (GenOs, OsteoBiol by Tecnoss, Coazze, Italy) [2].

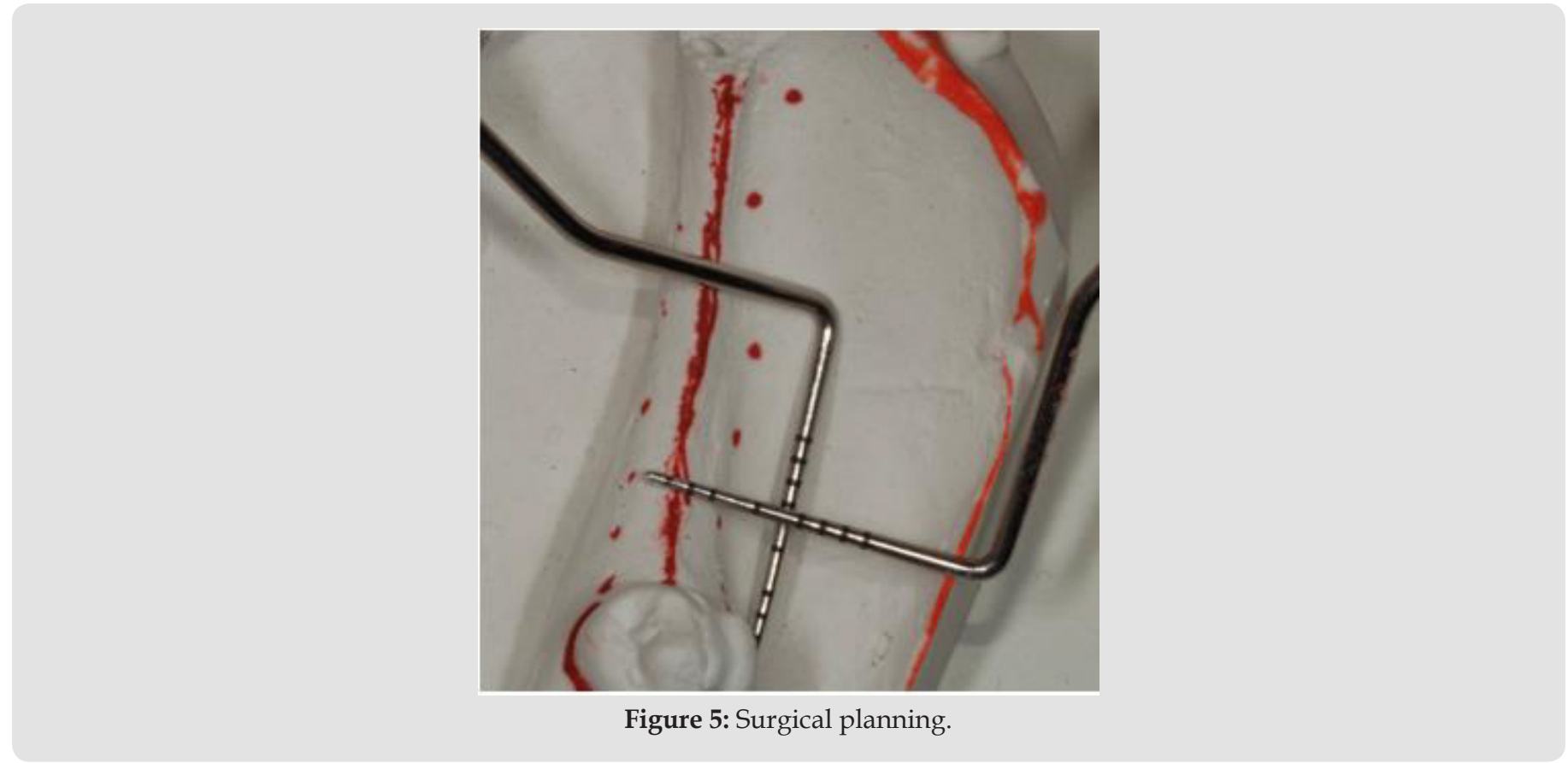

\section{Surgical Procedure}

After local anesthesia with Articaine with adrenaline $1.200 .00 \mathrm{a}$ mid- crestal incision was carried out from the distal of the bicuspid all the way to the area of the second molar, buccal and lingual full thickness flaps were raised exposing the underlying bone (Figure 6) [3].
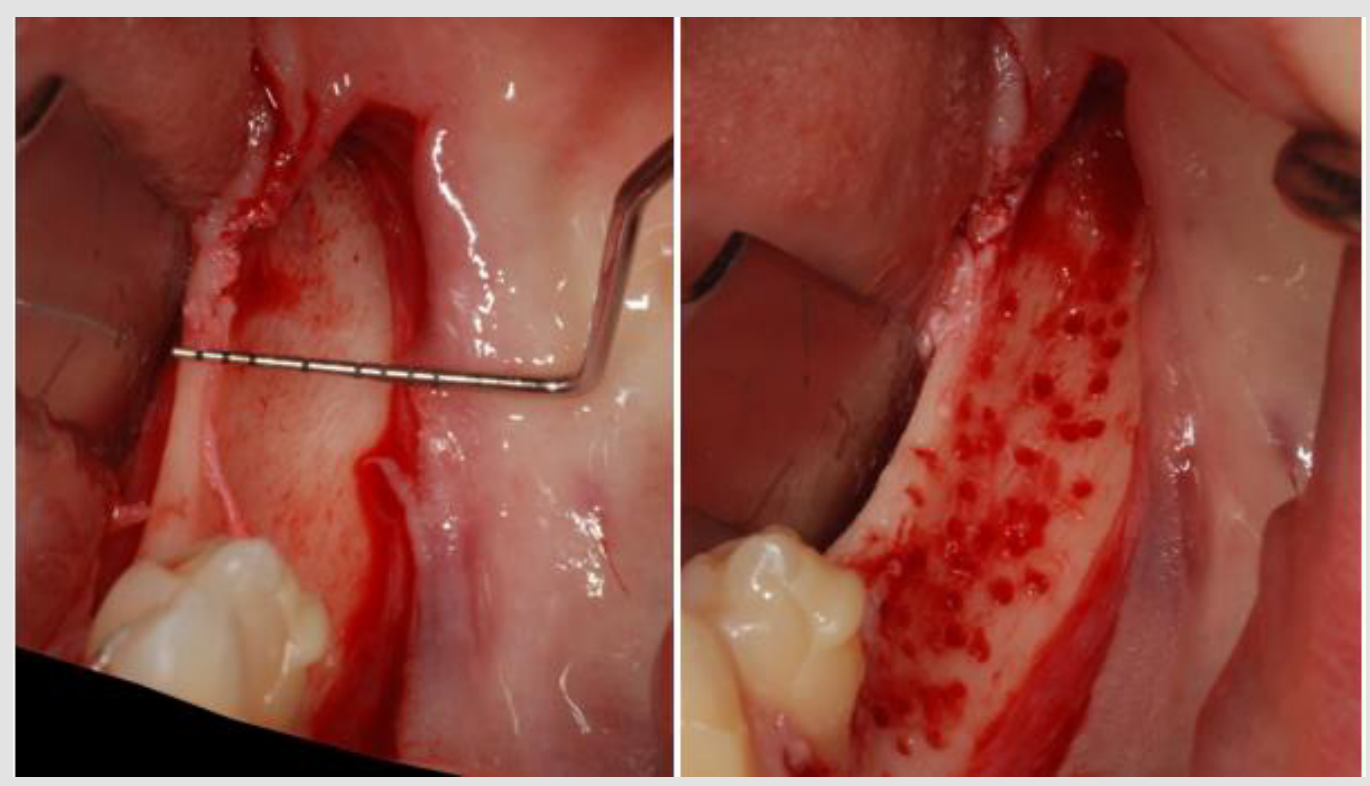

Figure 6: Edentulous ridge exposed "and bukerelled". 
The edentulous ridge, as showed by the CBCT presented only the lingual wall while the buccal bone was completely absent. With the aid of a small diamond bur several intra marrow penetration were performed in order to create some bleeding and to create a favorable situation for the bone graft. Autogenous bone was collected from the distal portion of the jaw (where would not be possible to place an implant) and mixed with the biomaterial (Figure 7) [4].

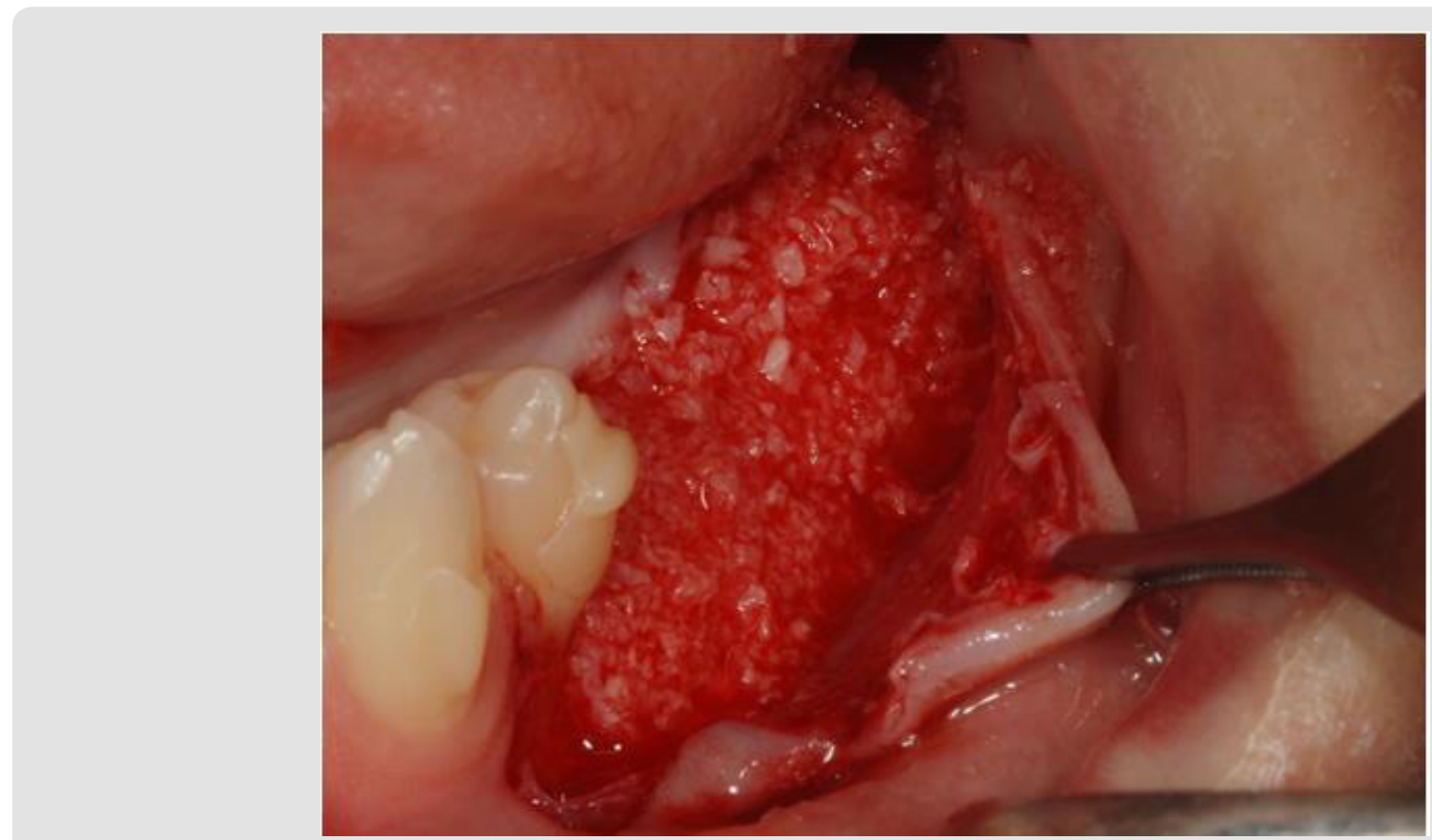

Figure 7: Bone graft in place.

Once the graft was completed the buccal and lingual flaps were extended through a brushing technique with an apico coronal movement of the periosteal elevator and the cortical lamina was cut, shaped and adjusted to fit the area (Figure 8) Flaps were than secured with 4.0 Vicryl absorbable sutures to secure an uneventful healing (Figure 9). Post-operative instructions included use of Amoxicillin (Augmentin 1 gr. X day for 7 days) and antiinflammatory on demand. Six months after bone augmentation the ridge had a new shape allowing the placement of a standard 4.1 diameter dental implant
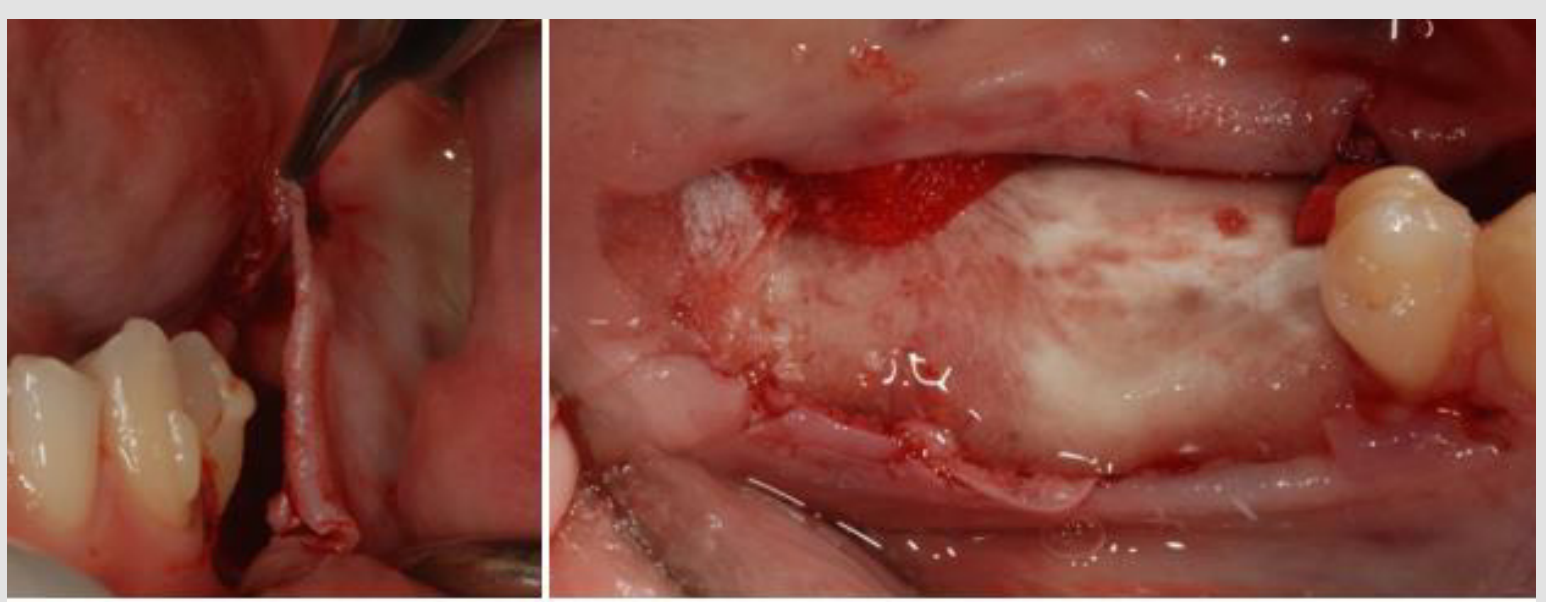

Figure 8: Flap adaptation after brushing and cortical lamina in place. 


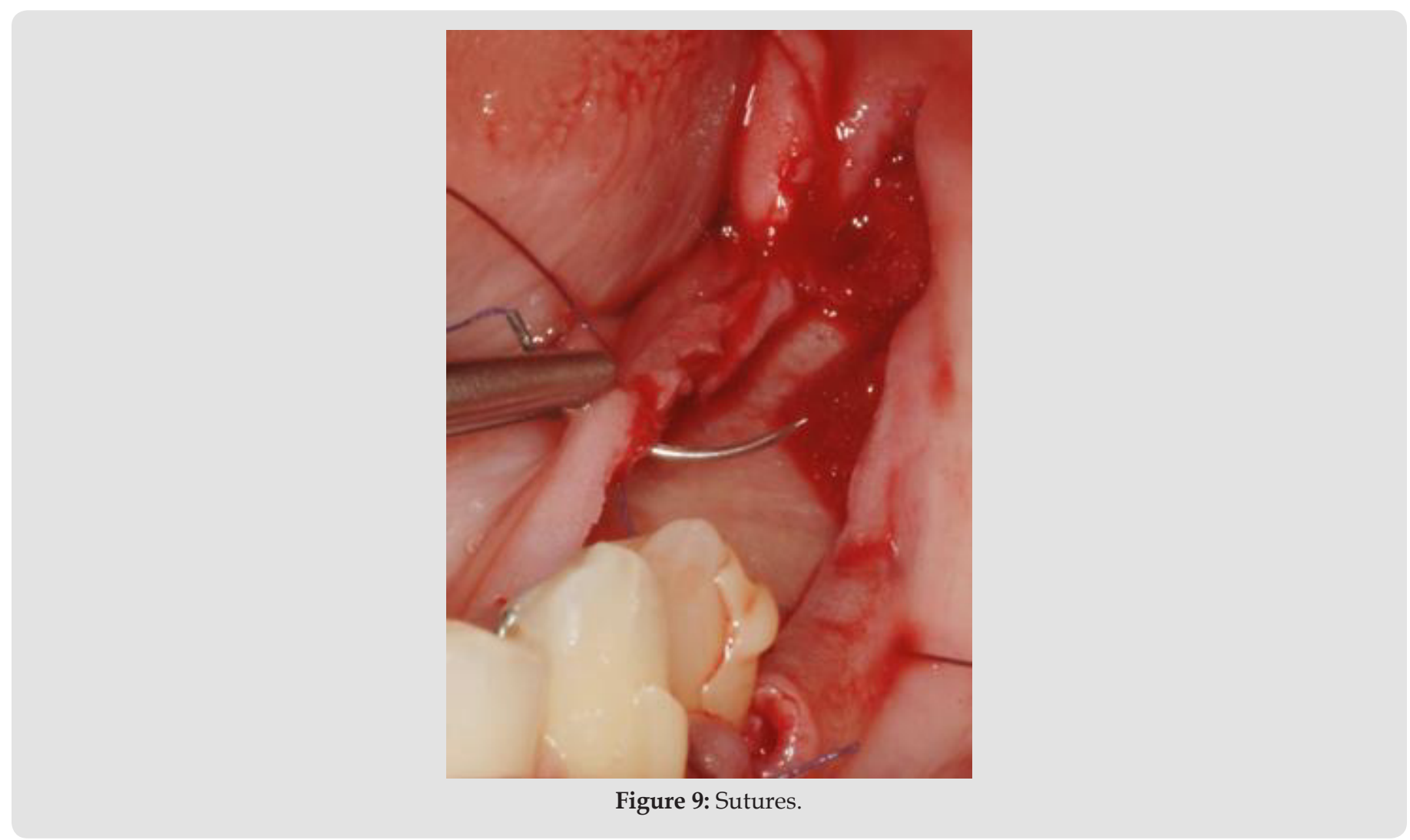

(Biaggini Medical Devices, Arcola, Italy), the ridge showed now a width of $7 \mathrm{~mm}$ as compared to the $2 \mathrm{~mm}$ at baseline (Figure 10). Three months later the implant was exposed and a healing abutment was connected associating and apical repositioned flap in order to replace the keratinized gingiva buccal to the abutment (Figure 11) One month after complete maturation of the soft tissue impressions were taken in order to fabricate a ceramic crown (Figure 12). Final restoration was delivered about nine months after the beginning of treatment (Figures 13\&14) but the radiograph and the clinical picture show how the primary objectives of treatment were met. Bone augmentation in order to accommodate a standard diameter implant in order to re-establish function and proper occlusion. A three year follow up shows a perfect stability of the regenerated area (Figure 15) [5].
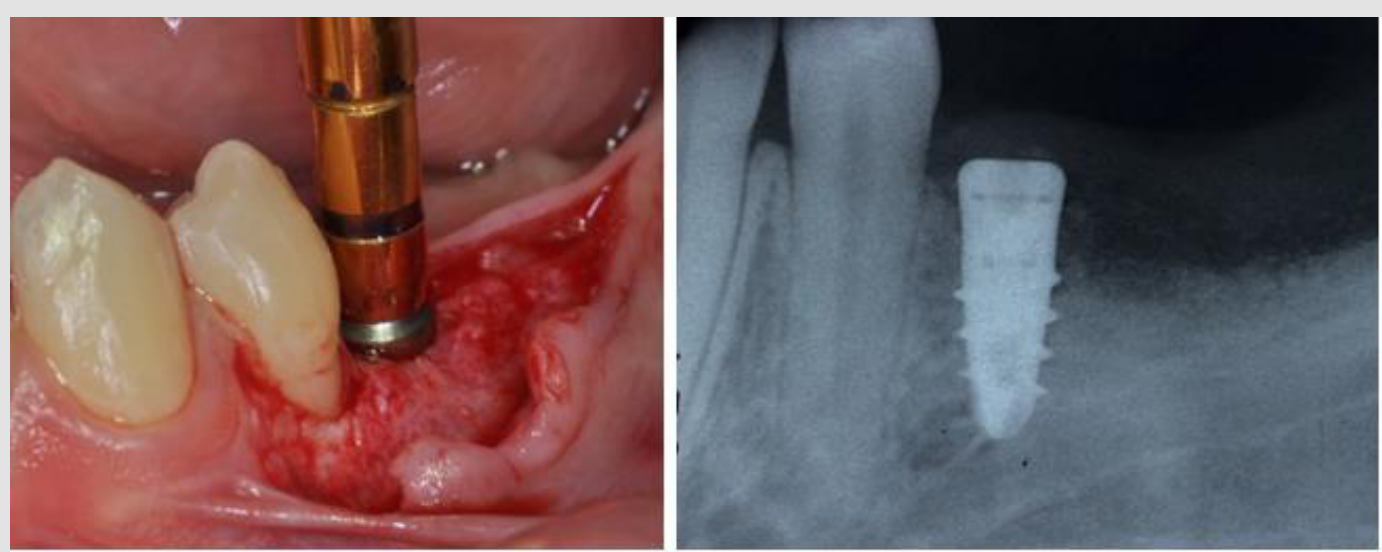

Figure 10: Implant in place 6 months after GBR. 


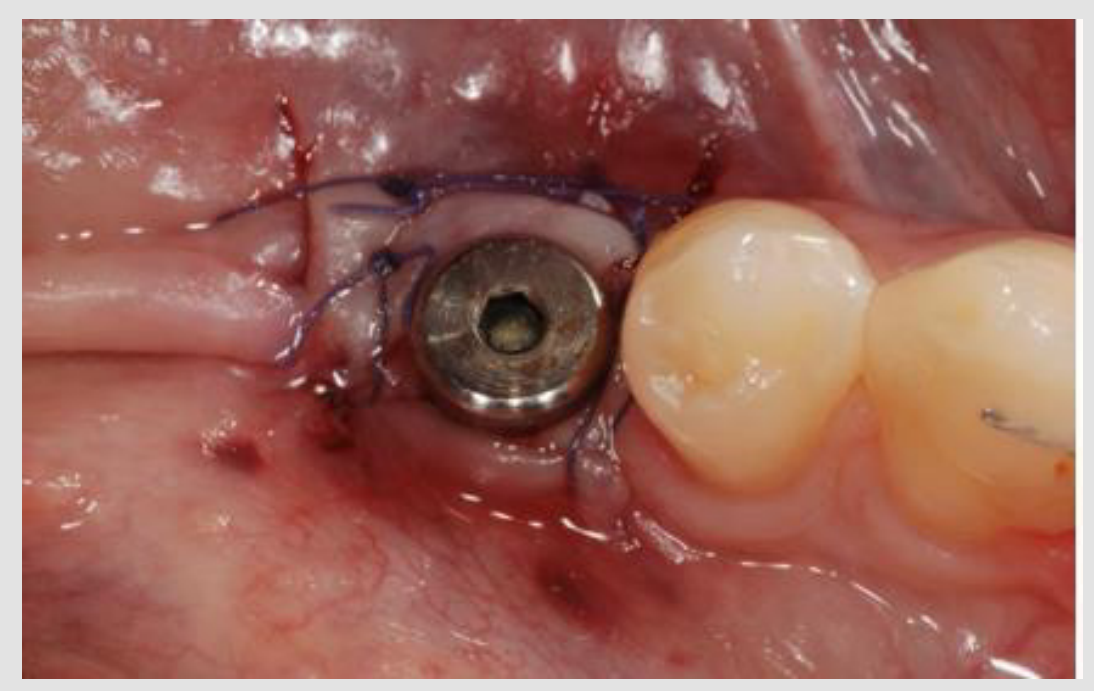

Figure 11: Second stage surgery.

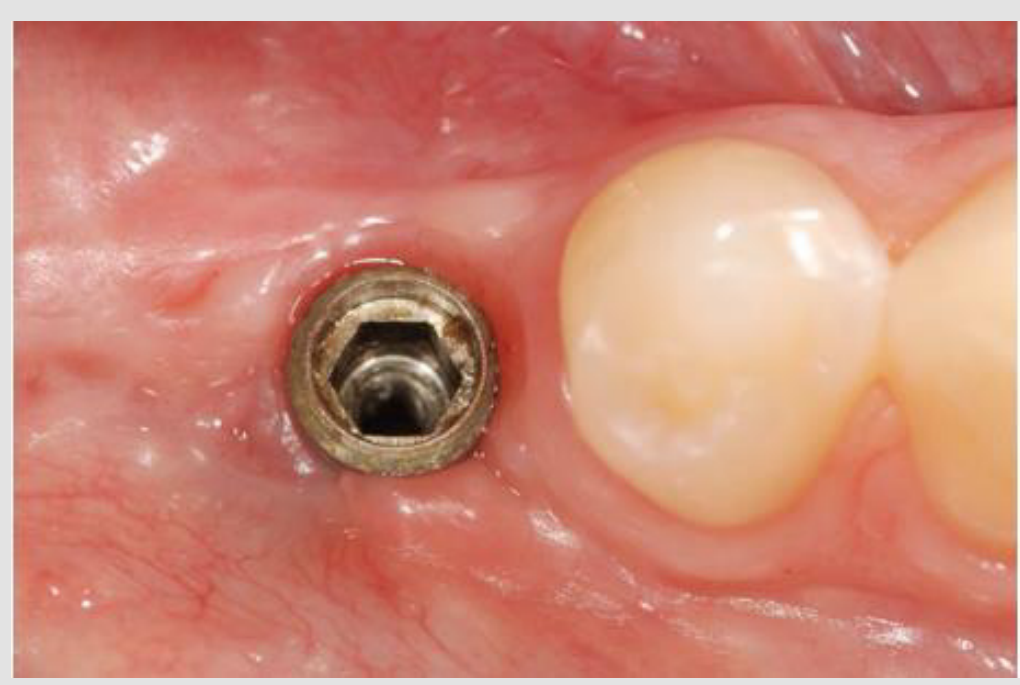

Figure 12: Maturation of the soft tissue.

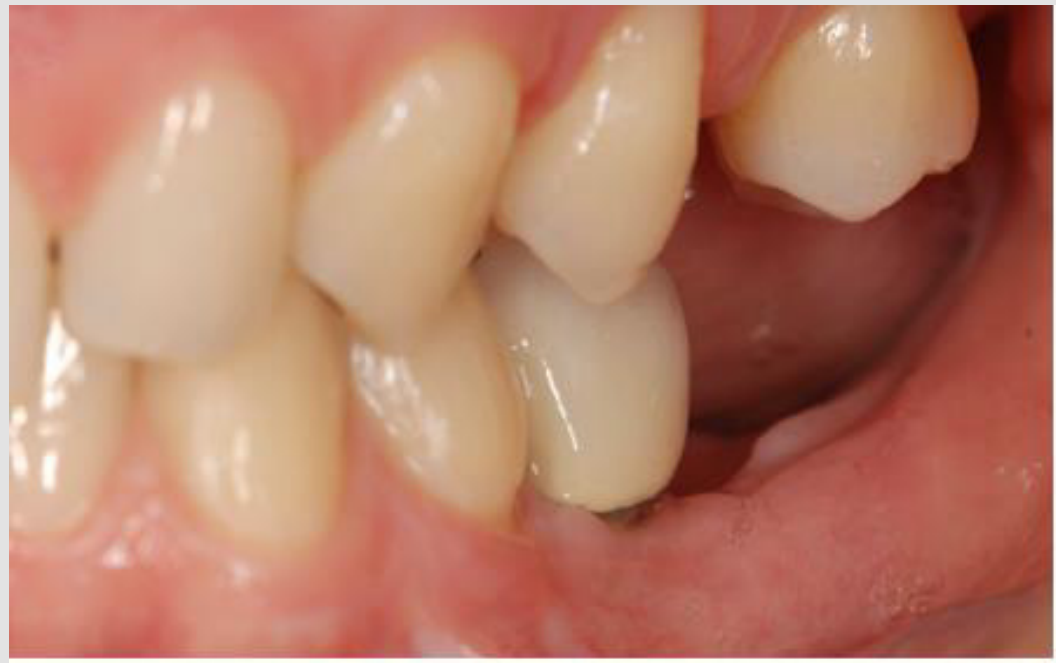

Figure 13: Final restoration. 


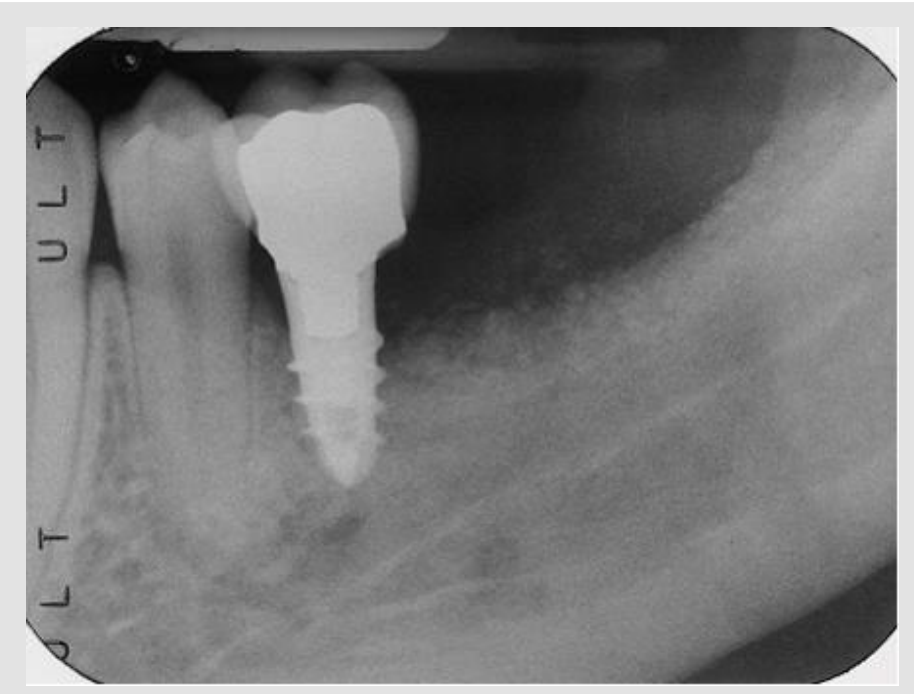

Figure 14: Radiograph of the crown (2017).
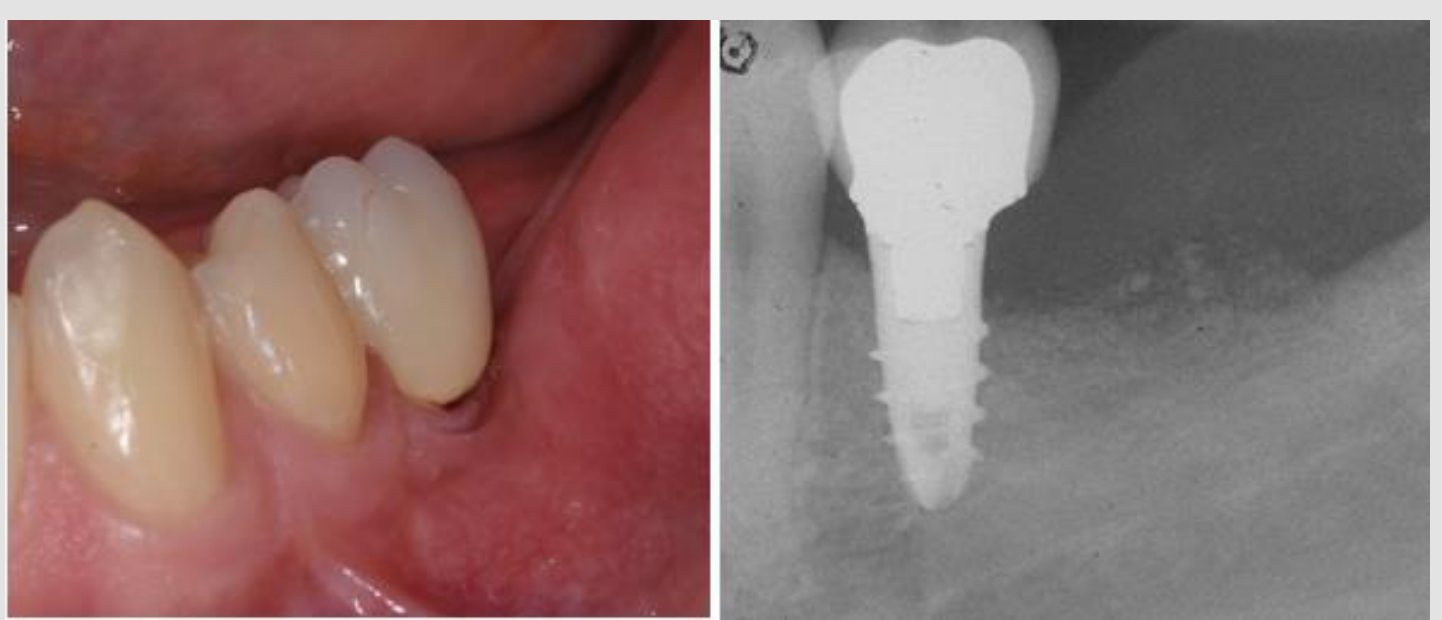

Figure 15: follow up 3 years after final restoration.

\section{Conclusion}

The cortical lamina technique represents nowadays a reliable solution for treatment of moderate to severe horizontal bone defects. In this specific case agenesis resulted in a severe horizontal defect. The lamina favored about $6 \mathrm{~mm}$ of horizontal bone regeneration that guaranteed the success of the case.

\section{References}

1. Wachtel H, Fickl S, Hinze M, Boltz W, Thalmair T (2013) The bone lamina technique: a novel approach for lateral ridge augmentation. A case series. Int J Perio Rest Dent 33(4): 491-497.
2. Rossi R, Ghezzi C, Tomecek M (2020) Cortical Lamina: a new device for the treatment of moderate and severe trideimensional bone and soft tissue defects. Int J Esthet Dent 15(4): 454-473.

3. Rossi R, Rancitelli D, Poli PP, Rasia da Polo M, Nannmark U, et al. (2016) The use of a collagenated porcine cortical lamina in the reconstruction of alveolar ridge defects: A clinical and histological study. Minerva Stomatol 65(5): 257-268.

4. Rossi R, Foce E, Scolavino S (2017) The cortical lamina technique a new option for ridge augmentation procedure: protocol and pilot case. J Leb Dent Ass 52(1).

5. Rossi R, Foce E (2019) Reconstruction of a Horizontal and vertical defect using the cortical lamina technique. Med Resear Arch. 
ISSN: 2574-1241

DOI: 10.26717/BJSTR.2021.35.005693

Roberto Rossi. Biomed J Sci \& Tech Res

\section{(c) Commons Attribution 4.0 License}

Submission Link: https://biomedres.us/submit-manuscript.php

$\begin{array}{ll}\text { BIOMEDICAL } & \text { Assets of Publishing with us } \\ \text { RESEARCHES } & \text { Global archiving of articles } \\ & \text { - Immediate, unrestricted online access } \\ & \text { - Rigorous Peer Review Process } \\ & \text { - Authors Retain Copyrights } \\ \end{array}$

